\title{
A Fully Integrated Physical Activity Sensing Circuit for Implantable Pacemakers
}

\author{
Alfredo Arnaud \\ GME-IIE Univ.de la República \\ Julio Herrera y Reissig 565/IIE \\ Montevideo - Uruguay \\ +598-2 7110974 - ext.113 \\ email: aarnaud@iie.edu.uy
}

\author{
Carlos Galup-Montoro \\ LCI-EEL Univ.Federal de Santa Catarina \\ 88040-900 Florianópolis - SC \\ Brazil \\ +55483319280 \\ email: carlos@eel.ufsc.br
}

\begin{abstract}
This paper shows the implementation of a fully integrated $\mathrm{G}_{\mathrm{m}}-\mathrm{C} 0.5$ $7 \mathrm{~Hz}$ bandpass filter-amplifier with gain $\mathrm{G}=400$, for a piezoelectric accelerometer which is part of a rate adaptive pacemaker. The fabricated circuit operates up to $2 \mathrm{~V}$ power supply, consumes only 230nA current, and achives $2.1 \mu \mathrm{V}_{\text {rms }}$ input noise. Detailed circuit specifications, measurements, and a comparative analysis of the system performance are presented.
\end{abstract}

\section{Categories and Subject Descriptors}

B.7.1 [Integrated Circuits]: Types and Design Style - Input/output circuits, VLSI.

\section{General Terms: Measurement, Design.}

Keywords: Analog design, CMOS, low-power, biomedical.

\section{INTRODUCTION}

Low power consumption is crucial in the case of pacemakers - the most widespread active implant - , where batteries need to last for years [1]. Since the replacement of batteries requires a surgical though simple - procedure, the need arises for minimizing power consumption to extend device lifetime. On the other hand, circuits must be extremely reliable since they may be life supporting devices for the patient. The realization of complex but reliable circuits restricted to a few micro-Amperes of current consumption is a major quest for the pacemaker manufacturer, that normally incorporates custom integrated circuits for the task. Not only due to power consumption, but also to reduce to a minimum the size of the device to be implanted. Thus, microelectronics technology is steadily contributing to the development of modern cardiac pacemakers, which are nowadays complex electronic circuits performing several sensing, control, and stimulation functions [1,2] to reestablish a normal rhythm to a diseased heart. These functions include, among others, cardiac sensing channels, cardiac stimulus, battery sensing, telemetry, and also (physical) activity sensing $[1,2,3]$ which is the motivation behind this work.

Activity sensing is a measurement of the physical activity, used in the so-called adaptive pacemakers, which regulate the heart

Permission to make digital or hard copies of all or part of this work for personal or classroom use is granted without fee provided that copies are not made or distributed for profit or commercial advantage and that copies bear this notice and the full citation on the first page. To copy otherwise, or republish, to post on servers or to redistribute to lists, requires prior specific permission and/or a fee.

SBCCI'04, September 7-11, 2004, Pernambuco, Brazil.

Copyright 2004 ACM 1-58113-947-0/04/0009...\$5.00. stimulation rate according to the requirements of the patient. For example the heart should beat at a much higher frequency while running than while sleeping; during strenuous exercise the heart rate can increase $250 \%$ over its resting rate. If there is insufficient cardiac output, an active patient may become fatigued while doing exercise and may not be able to continue. Thus, rate adaptation will increase the quality of life in near half the pacemaker holders whose heart cannot self-establish its rate [1]. A simple but robust solution for activity sensing, is the use of an accelerometer registering body movement. Because it is non-invasive (the sensing device is located inside the pacemaker without direct contact with the human body), this is the preferred technique incorporated in most adaptive pacemakers either complimented with another sensed parameter like ventilation rate, venous $\mathrm{O}_{2}$ saturation, or impedance measurement among others [1].

This work deals with the design of an activity sensing integrated circuit doing the signal conditioning of a commercial piezoelectric accelerometer. The specified signal chain for the circuit is presented in Fig.1; its objective is to give an output proportional to the average amplitude of the mechanical movement of the patient in the band of interest from 0.5 to $7 \mathrm{~Hz}$. First there is a $2^{\text {nd }}$ order bandpass filteramplifier stage. Then a rectifier and a 3 -second time averaging are added to estimate signal amplitude. The task of Fig.1 that appears simple, becomes difficult when dealing with normal pacemaker power consumption restrictions. Because motion signals are of very low frequency, the passive components -capacitors, resistors- for a traditional filter become too large to incorporate them into an integrated circuit [4]. A major challenge regarding this circuit is to reduce external components to a minimum, integrating all of them into a single chip. To overcome this problem, the selected circuit technique was continuous-time $\mathrm{G}_{\mathrm{m}}-\mathrm{C}$ filters [5], and series-parallel current division transconductors (OTAs) [6,7] were used to achieve the required transconductances (as much small as the equivalent to a $30 \mathrm{G} \Omega$ resistor and with up to $\pm 500 \mathrm{mV}$ linear range).

The critical block in the signal chain of Fig.1 is the bandpass filteramplifier because at the rectifier and time averaging stage, noise is no longer critical and the transfer function is simpler. Throughout this work the focus will be on the bandpass amplifier, and the complete design and test measurements for this stage will be presented. Moreover, a very simple rectifier and time averaging

design were also simulated to evaluate overall system area and power consumption in section 5 . In the following section, circuit specifications are presented, and bandpass-amplifier design and topology are then shown in section 3 . This circuit as well as isolated OTA structures for test purposes were fabricated and measured. Measurements are presented in section 4 while a performance comparison of this and other similar filters is discussed in section 5 . 


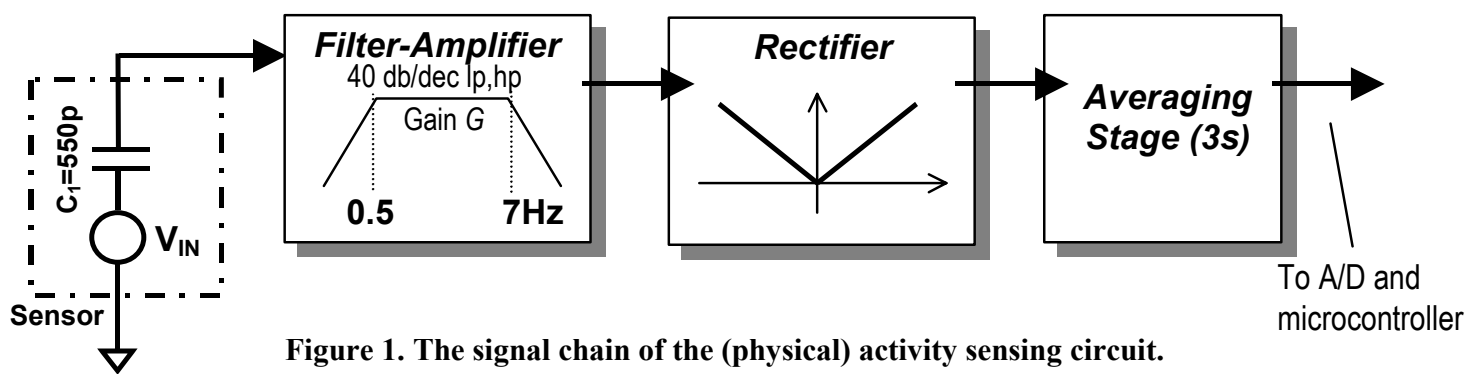

\section{THE SENSING ELEMENT \& SYSTEM SPECIFICATIONS}

Although several kinds of transducers exist [8,9] for sensing acceleration, we will limit the analysis to piezoelectric ones [8] because they fulfill size, and power consumption requirements, for implantable devices although their cost may be elevated. In a piezoelectric element appears charge on its nodes proportional to the (acceleration-induced) mechanical stress. Since the sensing material is an isolator, the transducer acts as a capacitor. From the circuit perspective, the input source can be considered either as a charge generator or as a voltage source in series with a capacitor, as in Fig.1. The accelerometer to be employed is a miniature single axis one selected because there is experience in its usage, but also a dedicated search for a better option was carried out without success. In Table 1, detailed specifications are shown. The charge sensitivity and capacitance of the sensor are $1.5 \mathrm{pC} / \mathrm{g}$, and $550 \mathrm{pF}$, respectively, which is equivalent to a $3.5 \mathrm{mV} / \mathrm{g}$ sensitivity in the connection scheme of Fig.1.

The approximated range of accelerations, appearing at chest level due to normal human exercise, is $0.007 \mathrm{~g}_{\text {peak }}$ to $0.34 \mathrm{~g}_{\text {peak }}$. The frequency band of interest $-0.5 \mathrm{~Hz}$ to $7 \mathrm{~Hz}$ - corresponds to figures reported in [1] for several studies on acceleration for various activities for the human body. Owing to the force of gravity, physical activity acceleration signals may be accompanied by much higher steps of up to at least $\pm 1 \mathrm{~g}$ that should be removed. A $2.8 \mathrm{~V}$ (nominal) lithium-iodine battery normally powers modern pacemakers. Battery voltage decays with time and the pacemaker should be fully operational up to a $2 \mathrm{~V}$ power supply to guarantee a reasonable time from the low battery condition detection, to pacemaker substitution[1,2]. The activity sensing circuit must operate up to this voltage with a power consumption budget restricted to less than $3 \mu \mathrm{A}[2,3]$. In Table 2, a resume of specifications for the bandpass amplifier is presented. Noise specifications correspond to an in-band rms value equal to the rms voltage produced by the minimum $0.007 \mathrm{~g}$ acceleration input to be detected (typ.- $24 \mu \mathrm{V}_{\text {peak }}$ ). A gain $\mathrm{G}=400$ is selected so that this minimum input signal gives an output voltage higher than the maximum estimated $5 \mathrm{mV}$ output offset.

For implantable applications, a piezoelectric transducer is an ideal choice because it has no power consumption of its own, only that of the signal conditioning circuitry. It can be found in very small packages for OEM applications and it has an adequate sensitivity. However, the signal conditioning circuit presents several challenges:

- At $0.5 \mathrm{~Hz}$, the $550 \mathrm{pF}$ sensor capacitance represents a $580 \mathrm{M} \Omega$ series impedance. Also note in Fig.1 that the upper node of the accelerometer is floating unless the measuring circuit provides some kind of virtual ground or DC bias connection. So the sensor cannot be simply connected to an infinite input impedance amplifier like a MOS gate input amplifier.

- Although a pacemaker is a self-contained circuit in a titanium case very close to an ideal Faraday jail, capacitive or inductive coupled noise may strongly affect the sensor due to its enormous output impedance.

- The circuit must operate at low voltage, with extremely low power consumption, it must be low-noise, and with a reduced offset.

Table 1. Piezoelectric sensor data provided by the manufacturer.

\begin{tabular}{|l|c|c|c|}
\hline Specification & Min. & Typ. & Max. \\
\hline ChargeSensitivity $[\mathrm{pC} / \mathrm{g}]$ & 1.4 & 1.9 & 2.4 \\
\hline Capacitance & & $550 \mathrm{pF}$ & \\
\hline Transverse response & & & $5 \%$ \\
\hline Resistance $\left(25^{\circ} \mathrm{C}\right)$ & $10 \mathrm{G} \Omega$ & & \\
\hline Resistance $\left(150^{\circ} \mathrm{C}\right)$ & $100 \mathrm{M} \Omega$ & & \\
\hline Mechanic Resonance & & $9 \mathrm{kHz}$ & \\
\hline
\end{tabular}

Table 2. Circuit specifications for the bandpass filteramplifier. $\quad$ (1) Whole system of Fig.1.

\begin{tabular}{|l|c|}
\hline Specification & Requirement \\
\hline Supply Voltage & $2.8-2.0 \mathrm{~V}$ \\
\hline Acceleration Range & $0.007-0.34 \mathrm{~g}_{\text {peak }}$ \\
\hline Input Voltage Range & $\left(24 \mu \mathrm{V}_{\text {peak }}-1.2 \mathrm{mV}_{\text {peak }}\right)$ \\
\hline Power Consumption & $<3 \mu \mathrm{A}^{(1)}$ \\
\hline Frequency Response & $0.5-7 \mathrm{~Hz}$ Bandpass $40 \mathrm{~dB} / \mathrm{dec}$ \\
\hline Input Referred Noise & $<12 \mu \mathrm{V}_{\text {rms }}$ \\
\hline Output Offset & $<5 \mathrm{mV}$ \\
\hline Total Gain & 400 \\
\hline Others: - No external components. \\
- Relaxed tolerance in gain and poles position. \\
\hline
\end{tabular}

- All these restrictions must be overcome without the use of external passive components.

Since fully integrated continuous-time filters in the sub-Hz range are a modern research topic [10-14], the last issue is expected to be the hardest challenge because novel techniques must be combined with low-noise and micro-power restrictions. 


\section{CIRCUIT DESCRIPTION}

The bandpass filter topology is shown in Fig.2; it has two cascaded single-ended stages with a total gain of $G=385$ : a preamplifier stage with a gain of $G_{I}=46.4$ formed by $G_{m 1}, G_{m 2}, G_{m 3}, \mathrm{C}_{1}, \mathrm{C}_{2}$, and a gain stage with a gain of $\mathrm{G}_{2}=8.4$ formed by $G_{m 4}, G_{m 5}, G_{m 6}, C_{3}, \mathrm{C}_{4}$. Each stage is composed of a lowpass gain structure (given by $G_{m 1(4)}$, $G_{m 2(5)}, \mathrm{C}_{2(4)}$ ) similar to that proposed in [14] for a capacitive microphone, and a DC cancellation loop (given by $G_{m 3(6)}, \mathrm{C}_{1(3)}$ ). Note in Fig. 2 that the sensor capacitance itself is used in the filter, taking advantage of a $550 \mathrm{pF}$ capacitor -much greater than common integrated ones-. The preamplifier DC cancellation loop also provides a DC virtual ground for the upper node of the accelerometer, eliminating in this way the need for any resistor connected to ground. The transfer function $H_{1(2)}(\omega)$ of each stage of the amplifier is bandpass [5]:

$$
H_{1(2)}=\frac{Q \omega_{0}}{k} \cdot \frac{j \omega \cdot \omega_{0} / Q}{\omega_{0}^{2}+j \omega \cdot \omega_{0} / Q-\omega^{2}}
$$

with quality factor $\mathrm{Q}$, and center frequency $\omega_{0}$ :

$$
\begin{gathered}
\omega_{0}=\sqrt{\frac{G_{m 1} G_{m 3}}{C_{1} C_{2}}} \approx \sqrt{\frac{G_{m 4} G_{m 6}}{C_{3} C_{4}}} \approx 1.88 \mathrm{~Hz} \\
Q=\sqrt{\frac{G_{m 1} G_{m 3} C_{2}}{G_{m 2}^{2} C_{1}}} \approx \sqrt{\frac{G_{m 4} G_{m 6} C_{4}}{G_{m 5}^{2} C_{3}}} \approx 0.25
\end{gathered}
$$

$k$ is defined as $k=\frac{G_{m 3(6)}}{C_{1(3)}}$ so the gain at the center frequency of each stage is $G_{1(2)} \approx \frac{\omega_{0} Q C_{1(3)}}{G_{m 3(6)}}$. The system was simulated to be stable, with a $68^{\circ}$ phase margin. The capacitors, and OTAs $G_{m l}$ to $G_{m 6}$, where designed with the following criterion:

- Noise is critical, mostly determined by $G_{m l}$; so, $G_{m l}$ transconductance was designed to minimize noise, according to area and current consumption budget. $G_{m l}$ is a standard symmetrical OTA.

- As much gain as possible was assigned to the preamplifier.

- $\mathrm{G}_{\mathrm{m} 6}$ was a minimum offset oriented design and $\mathrm{C}_{4}=250 \mathrm{pF}$ was selected as the largest reasonable value.

The rest of the capacitors were $50 \mathrm{pF}$ while OTAs $\mathrm{G}_{\mathrm{m} 2}$ to $\mathrm{G}_{\mathrm{m} 6}$ were designed using the methodology proposed in [7] according to their required linear range and transconductance.

Apart from $G_{m l}$, the rest of the transconductors are implemented using series-parallel current division [6,7]. For example, in Fig.3 the architecture for $G_{m 6}$ is shown. It is a symmetrical OTA with a linearized input pair [15], and a current division factor $N^{2}=784$. The effective transconductance is calculated as

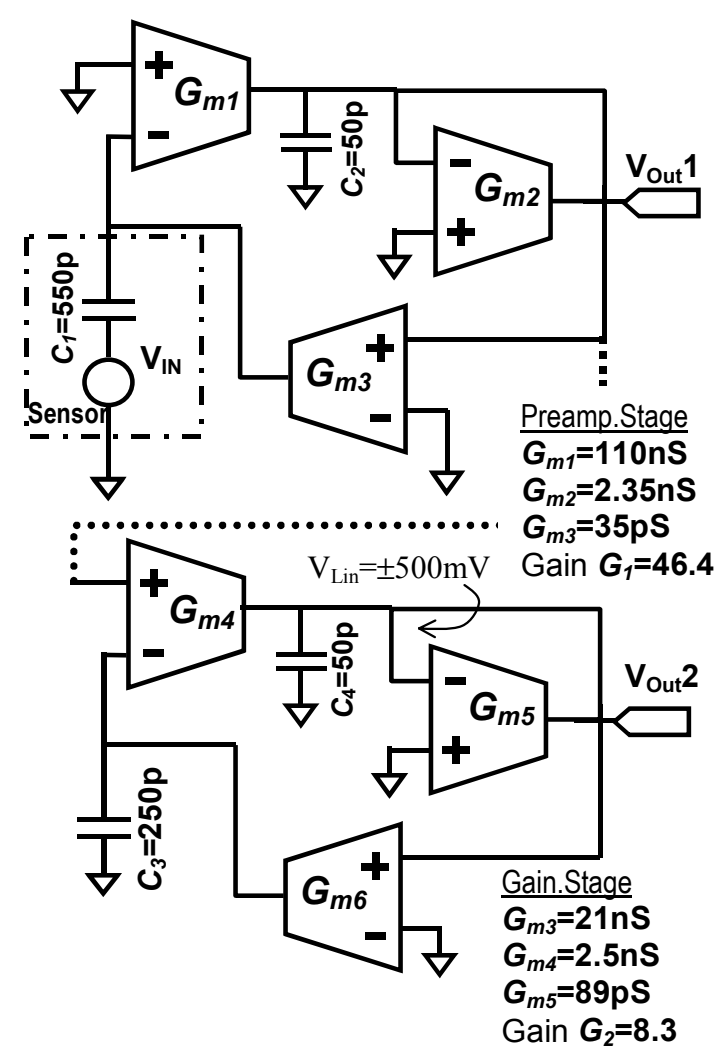

Figure 2. Circuit topology of the bandpass filter-amplifier.

$G_{m 6}=g_{m_{-} e q} / N^{2}$, where $g_{m_{-} e q}=70 \mathrm{nS}$ is the equivalent transconductance of the linearized input pair. Since their required linear range is smaller, $G_{m 2}, G_{m 3}, G_{m 4}$, are implemented with nondegenerated differential input pairs. Since the required division factor for $G_{m 4}, G_{m 5}$ is not too large, transistor $\mathrm{M}_{2}$ " is composed of a rectangular array of unitary transistors. For example, the gain of the NMOS current mirror $\mathrm{M}_{2}$ ": $\mathrm{M}_{2}{ }^{\prime}$ in $G_{m 4}$ is $1: 8$. This gain is obtained with $\mathrm{M}_{2}$ ' as an array of 28 unitary transistors in parallel while, $\mathrm{M}_{2}$ "'is composed of a 7-parallel-by-2-series array of unitary transistors. $\mathrm{M}_{2}$ " is then equivalent to a $3 \frac{1}{2}$ parallel array of unit transistors [16]. These numbers were chosen in order to reuse other layout blocks of the circuit. Finally, at the output of each stage $\left(V_{\text {Out }}, V_{\text {Out }}\right)$, the unity gain buffers that appear in Fig.4 were placed for test purpose only.

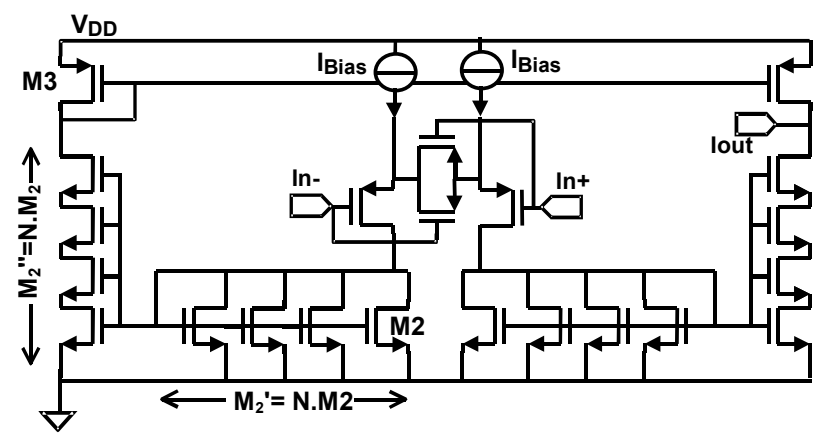

Figure 3. Circuit schematic for $G_{m 6}$ including series-parallel current division and linearized differential input pair. 
Table 3. Measurement results for fabricated transconductors: estimated(measured) transconductance, linear range $V_{\text {Lin }}([7]$ error $\alpha<5 \%$ ), estimated (measured) input referred noise in the passband, measured offset, estimated current consumption, and total area, for the OTAs. $G_{m 5}, G_{m 6}$ share the input pair but use different output current mirrors.

\begin{tabular}{|c|c|c|c|c|c|c|}
\hline OTA & Transc. & $\begin{array}{l}\text { Linearity } \\
V_{\text {Lin }}[\mathrm{mV}]\end{array}$ & $\begin{array}{c}\text { Input noise. } \\
{\left[\mu V_{\mathrm{rms}}\right]}\end{array}$ & $\begin{array}{c}\text { Input Offset } \\
\sigma_{\text {Voff }}[\mathrm{mV}]\end{array}$ & $\begin{array}{l}\text { Current } \\
\text { Cons.[nA] }\end{array}$ & $\begin{array}{c}\text { Area } \\
{\left[\mathrm{mm}^{2}\right]}\end{array}$ \\
\hline$G_{m 1}$ & $110(110) n S$ & 60 & $5(4)$ & 1.1 & 14 & .019 \\
\hline$G_{m 2}$ & $2.35(2.58) \mathrm{nS}$ & 150 & 42 & 4.4 & 43 & .040 \\
\hline$G_{m 3}$ & 35(33)pS & 150 & $163(130)$ & 2.1 & 42 & .092 \\
\hline$G_{m 4}$ & $21 n S$ & 150 & & & 47 & .051 \\
\hline$G_{m 5}$ & $2.4(2.8) \mathrm{nS}$ & 500 & & 9.1 & \multirow{2}{*}{44} & \multirow{2}{*}{.18} \\
\hline$G_{m 6}$ & $89(100) p S$ & 500 & & 6.8 & & \\
\hline
\end{tabular}

\section{FILTER MEASUREMENT RESULTS}

The above described bandpass filter-amplifier was fabricated in a standard $0.8 \mu \mathrm{m}$ CMOS technology, and tested. In Fig.4 a microphotograph of the circuit occupying $0.7 \mathrm{~mm}^{2}$ is shown. Fig. 5 shows the expected and measured overall transfer function of the filter. The center frequency was measured as $1.8 \mathrm{~Hz}$. The simple circuit in Fig. 6 was used to simulate the accelerometer, using an external function generator because a calibrated movement generator was not available. The voltage divider $R_{A}-R_{B}$ allows us to comfortably simulate input voltages from a few $\mu \mathrm{V}$ to a few $\mathrm{mV}$, using a standard function generator. Measured input referred noise was only $2.1 \mu \mathrm{V}_{\text {rms }}$ and measured power consumption was only 229 nA. A resume of bandpass filter-amplifier characteristics is shown in Table 4. The graph in Fig.7 shows the time response of the filter-amplifier with the accelerometer connected to its input, while shaking the whole system at approximately $2 \mathrm{~Hz}$.

Isolated transconductors where also fabricated for test purpose. Several measured and estimated characteristics are summarized in Table 3. It should be highlighted that the reduced input offset of the OTAs is obtained with moderate area and power consumption, even for the case of a transconductor of only $33 \mathrm{pS}$, or $G_{m 6}$ of only $89 \mathrm{nS}$ with a $\pm 500 \mathrm{mV}$ linear range. Ten circuit samples from the same batch were used to calculate $\sigma_{\text {Voff }}$ in Table 3 .

To complete the system test, the accelerometer connected to the fabricated bandpass amplifier, with the addition of an external fullwave rectifier and 15 s time averaging ${ }^{1}$, was inserted into a batterypowered closed container to do a field test of the activity sensing system. The idea is to carry the circuit, strapped at chest level, while doing different physical activities to check whether it is capable of distinguishing between them. The output voltage was registered with the aid of a small pocket multimeter. The results are summarized in Table 5. The measurements seem adequate for the inclusion of the circuit in a high performance rate adaptive pacemaker.

\footnotetext{
${ }^{1}$ In comparison to Fig.1, the integration time was increased to comfortably measure the system output at different physical activities.
}

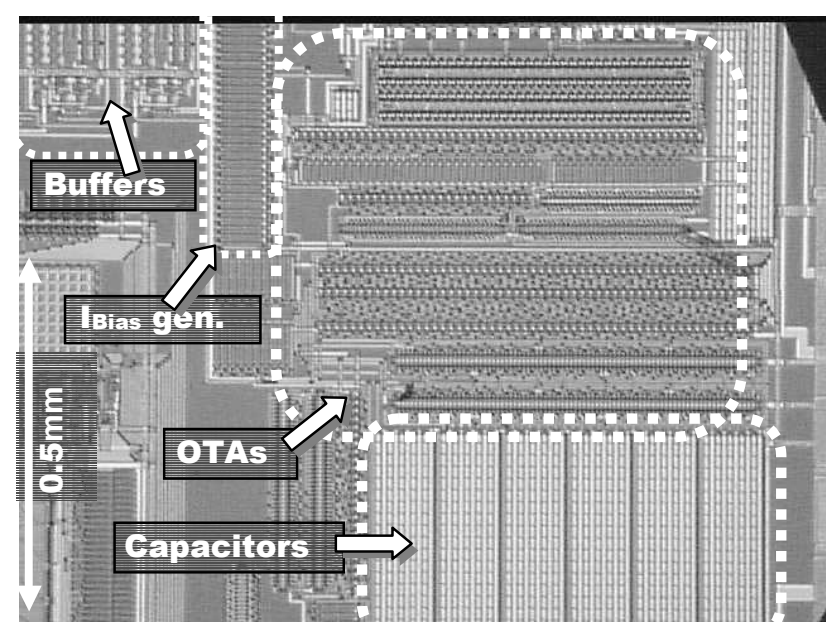

Figure 4. A microphotograph of the fabricated circuit. OTAs, capacitors, (test)buffers, and the bias current generation block are shown.



Figure 5. Measured filter response. 


\section{CONCLUSIONS}

A fully integrated $\mathrm{G}_{\mathrm{m}}-\mathrm{C}, 0.5-7 \mathrm{~Hz}, \mathrm{CMOS}$ bandpass filter-amplifier has been presented. Large time constants were obtained using seriesparallel division of current in symmetrical OTAs to achieve low transconductances with an extended linear range. The measured and predicted performance of the filter resulted in a very good solution in terms of current consumption, noise, offset, and occupied area. Its low input referred noise, and power consumption should be highlighted. A complete accelerometer-based activity sensing system using this filter was tested while realizing different physical activities, showing that it is suitable for incorporation in modern rate adaptive pacemakers. A comparative analysis of circuit performance is shown in Table 5, where the main characteristics of several micropower filters are summarized. The first row relates to the activity sensing circuit here presented, including the bandpass amplifier, and rectifier-time average stage ${ }^{2}$. Row (\#2) presents data also from an activity sensing circuit using continuous-time techniques but requiring a large number of external components [3]. Row (\#3) contains the information related to a switched-capacitor filter, rectifier, and time averaging used for the same purpose, based on a piezoresistive accelerometer [17]. The three circuits are different approaches to the same problem but the $\mathrm{G}_{\mathrm{m}}-\mathrm{C}$ filter using seriesparallel current division shows a considerable reduction in power consumption and input noise, while using no external elements. The occupied area has been reduced but the circuits in rows(\#2,3) were fabricated in a $2.4 \mu \mathrm{m}$ technology. Rows $(\# 4,5)$ contain information about two filters - which are intended to form part of biomedical devices - and have a set of specifications close to those of the physical activity sensing circuit. The first is a $2.4 \mathrm{~Hz}$ low pass filter, presented by Solis Bustos et al [12] using combined continuoustime techniques. The circuit is compact in area while implementing a high order transfer function with a $60-\mathrm{dB}$ dynamic range performance. This filter requires more power consumption and input noise is higher in comparison to the filter in row (\#1). The reason for this is probably the use of capacitor scaling, and partial current cancellation OTAs. The data in row (\#5) correspond to a low-power front end for a pacemaker atrial sensing channel [13]. It is a bandpass filter-amplifier centered at $110 \mathrm{~Hz}$, with several special characteristics. The circuit combines a continuous-time preamplifier-antialiasing stage at the input, followed by a $3^{\text {rd }}$ order switched capacitor stage. 4 external filter ${ }^{3}$ components are used in the circuit which also takes advantage of high resistivity poly layers to implement $\mathrm{M} \Omega$ s resistors in the preamplifier. The resulting circuit is very compact in area, with a very low power consumption and an extremely low input referred noise if we take into account that the bandwidth of this filter is approximately 9 times that of the filter in row (\#1). This further noise reduction is possible in this case due to the reduced flicker noise at the much higher frequency bandpass.

An overall conclusion is that the system here presented improves the performance of previously designed activity sensing circuits in $[3,17]$. Its performance is also comparable to other high-end modern filters with close specifications [12,13].

${ }^{2}$ Simulated but not tested fully-integrated rectifier and 3 s time averaging stage are also included.

${ }^{3}$ But the use of at least 2 external components is mandatory in atrial sensing channel for safety purposes.

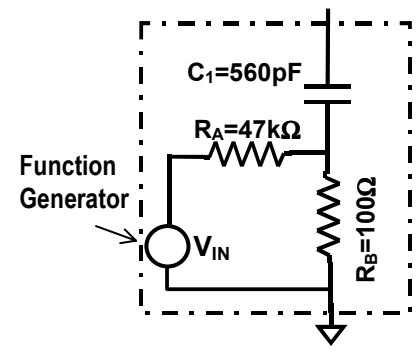

Figure 6: A simple circuit used to emulate the sensor output with a standard function generator.

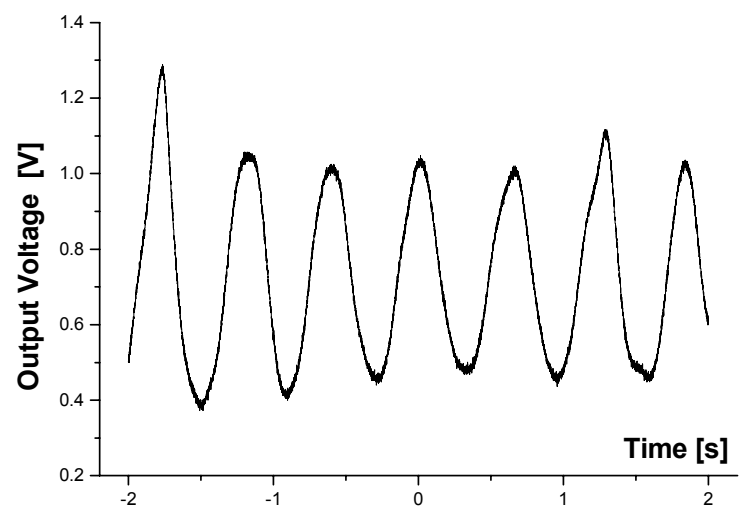

Figure 7. Filter output while shaking the system at approximately $2 \mathrm{~Hz}$ with the piezoelectric accelerometer connected at the input.

Table 4. Measured bandpass amplifier characteristics. ${ }^{[1]}$ estimated with measured offset for $G_{m 6}$ in Table 3 .

\begin{tabular}{|l|l|}
\hline Speciffication & Value \\
\hline Bandpass Frequency & $2^{\text {nd }}$ order $0.5-7 \mathrm{~Hz}$ \\
\hline Gain & 390 \\
\hline Input noise & $2.1 \mu \mathrm{V}_{\text {rms }}$ \\
\hline Operating Voltage & $2.0-2.8 \mathrm{~V}$ \\
\hline Current Consumption & $229 \mathrm{nA}$ \\
\hline Occupied Area & $0.78 \mathrm{~mm}^{2}$ \\
\hline
\end{tabular}

Table 5. Activity estimation measurements, using the fabricated circuit and external rectifier and $15 \mathrm{~s}$ time average.

\begin{tabular}{|c|c|}
\hline Physical Activity & Syst.Output \\
\hline Sleeping & $0 \mathrm{mV}$ \\
\hline Working on a Computer & $30 \mathrm{mV}$ \\
\hline Walking (slow) & $44 \mathrm{mV}$ \\
\hline Walking (normal) & $86 \mathrm{mV}$ \\
\hline Walking (fast) & $210 \mathrm{mV}$ \\
\hline Climbing up stairs & $95 \mathrm{mV}$ \\
\hline Going down stairs & $82 \mathrm{mV}$ \\
\hline Climbing up stairs (fast) & $200 \mathrm{mV}$ \\
\hline Running $(10 \mathrm{~km} / \mathrm{h})$ & $423 \mathrm{mV}$ \\
\hline
\end{tabular}


The main advantage of $\mathrm{G}_{\mathrm{m}}-\mathrm{C}$ filters is that they are extremely simple allowing a reduced power consumption and noise. Finally, seriesparallel OTAs also allow the implementation of $\mathrm{G}_{\mathrm{m}}-\mathrm{C}$ filters with a reduced mismatch offset. However, there are not enough elements to include offset in the final comparative analysis.

\section{ACKNOWLEDGMENTS}

The authors are grateful to CONICYT, Uruguayan agency for scientific development for their financial support.

\section{REFERENCES}

[1] J. G. Webster (Editor), Design of Cardiac Pacemakers, IEEE Press, New York, 1995. ISBN0-7803-1134-5.

[2] F.Silveira, D.Flandre, Low Power Analog CMOS for Cardiac Pacemakers - Design and Optimization in Bulk and SOI technologies, Kluwer Ac. Pub 2004, ISBN 140207719X

[3] A. Arnaud, M. Barú, G. Picún, F. Silveira, "Design of a Micropower Signal Conditioning Circuit for a Piezoresistive Acceleration Sensor", Procs. of the 1998 IEEE ISCAS, Monterey, USA, vol.I, pp. 269-272.

[4] W.H.G.Deguelle, "Limitations on the integration of analog filters below 10Hz" in Proc. ESSCIRC'88, 1988,pp.131-134.

[5] R.Schaumann, "Continuous-Time Integrated Filters - A Tutorial”, IEEE Proc., vol.136,Pt.G, pp184-190, Aug.1989.

[6] P.Kinget, M.Steyaert, J.Spiegel, "Full analog CMOS integration of very large time constants for synaptic transfer in neural networks", Analog Int.Circuits \& Signal Proc. vol.2, $\mathrm{n}^{\circ} 4$, pp.281-295, 1992.

[7] A.Arnaud, C.Galup-Montoro, "Pico-A/V range CMOS transconductors using series-parallel current division", Electronics Letters, v. 39, nº18, p.1295-1296, September 2003.

[8] N.Yazdi, F.Ayazi, K.Najafi, "Micromachined Inertial
Sensors", Procs.of the IEEE, vol.86, nº 8 , pp.1640-1659, Aug.1998.

[9] IEEE Press, Microsensors, New York, 1990.

[10] A.Veeravalli, E.Sánchez Sinencio, J.Silva Martínez, "A CMOS Transconductance Amplifier Architecture With Wide Tuning Range for Very Low Frequency Applications", IEEE JSSC, vol.37,nº, pp.776-781,Jun.2002.

[11] C.D.Salthouse, R.Sarpeshkar, "A Practical Micropower Programmable Bandpass Filter for use in Bionic Ears", IEEE JSSC, Vol.38,nº 1,pp.63-70, Jan.2003.

[12] S.Solís Bustos, J.Silva, F.Maloberti, E.Sánchez Sinencio, " $A$ 60dB Dynamic Range CMOS Sixth-Order 2.4Hz Low-Pass Filter for Medical Applications", TCAS-II, V.47, n¹2, pp.1391-98, Dec.2000.

[13] L.Lentola, A.Mozzi, A.Neviani, A. Baschirotto, "A $1 \mu$ A Front End for Pacemaker Atrial Sensing Channels With Early Sensing Capability". IEEE TCAS-II, vol.50, nº, Aug.2003.

[14] J.Silva-Martínez, J.Salcedo-Suñer, "IC Voltage to Current Transducers with Very Small Transconductance", Analog Int. Circuits \& Signal Processing vol.13, pp. 285-293, 1997.

[15] F. Krummenacher; N. Joehl, “ $A$ 4-MHz CMOS continuoustime filter with on-chip automatic tuning”, IEEE JSSC, vol.23, no.3, pp750-758, June 1988.

[16] Galup-Montoro, M. C. Schneider, and I. J. B. Loss, "Seriesparallel association of FET's for high gain and high frequency applications", IEEE JSSC, vol.29, nº, pp.1094-1101, September 1994.

[17] L.Reyes, D.Perciante, "Circuito a capacitores conmutados para el procesamiento de señal proveniente de un acelerómetro", Engineering degree project, F.Ingeniería UROU, Montevideo 2000.

Table 6. Comparative analysis of the system here presented (\#1); two other implementations of the same system (\#2,3); and two high performance filters for implantable devices $(\# 4,5)$.

\begin{tabular}{|c|c|c|c|c|c|c|c|}
\hline Circuit Description. & Technique & $\begin{array}{l}\text { Discrete } \\
\text { Elements }\end{array}$ & $\begin{array}{l}\text { Input } \\
\text { Noise }\end{array}$ & Gain & $\begin{array}{c}\text { Current } \\
\text { Consumption }\end{array}$ & $\begin{array}{l}\text { Supply } \\
\text { Voltage }\end{array}$ & $\begin{array}{l}\text { Area } \\
{\left[\mathrm{mm}^{2}\right]}\end{array}$ \\
\hline $\begin{array}{l}\text { (\#1) } 0.5-7 \mathrm{~Hz} \quad 2^{\text {nd }} \cdot \text { order } \\
\text { bandpass + rectifier + time } \\
\text { averaging. }\end{array}$ & $\begin{array}{c}\mathrm{Gm}_{\mathrm{m}} \mathrm{C} \text { using } \\
\text { series-parallel } \\
\text { division OTAs }\end{array}$ & no & $2-4 \mu V_{r m s}$ & 400 & $300 n A$ & $2-2.8 \mathrm{~V}$ & 1.2 \\
\hline $\begin{array}{l}\text { (\#2) }-0.5-7 \mathrm{~Hz} 1^{\text {st }} \cdot \text { order } \\
\text { bandpass }+ \text { rectifier }+ \text { time } \\
\text { averaging.[3] }\end{array}$ & $\begin{array}{c}\text { Combined } \\
\text { Continuous- time } \\
\text { techniques }\end{array}$ & 10 & $18 \mu V_{\text {rms }}$ & 2900 & $\begin{array}{c}3 \mu \mathrm{A}^{[\mathrm{a}]} \\
{[\mathrm{a} .5 \mu \mathrm{A} \text { sensor }}\end{array}$ & $2-2.8 \mathrm{~V}$ & 1.82 \\
\hline $\begin{array}{l}\text { (\#3) }-0.5-7 \mathrm{~Hz} 1^{\text {st }} \text { order } \\
\text { bandpass + rectifier.[17] }\end{array}$ & $\begin{array}{l}\text { Switched } \\
\text { Capacitors }\end{array}$ & $\begin{array}{l}2 \text { for time } \\
\text { averaging }\end{array}$ & n.a. & 510 & $\begin{array}{c}2.8 \mu \mathrm{A}^{[\mathrm{b}]} \\
{[\mathrm{b}] 1.5 \mu \mathrm{A} \text { sensor }}\end{array}$ & $2-2.8 \mathrm{~V}$ & 9 \\
\hline $\begin{array}{l}\text { (\#4) }-6^{\text {th }} \text { order, } 2.4 \mathrm{~Hz} \\
\text { lowpass filter. [12] }\end{array}$ & $\begin{array}{l}\mathrm{G}_{m}-\mathrm{C} w / \text { special } \\
\text { OTAs \& scaled } \\
\text { capacitors. }\end{array}$ & no & $<50 \mu V_{\text {rms }}$ & 0.3 & $3.3 \mu \mathrm{A}$ & $3 V$ & 1 \\
\hline $\begin{array}{l}\text { (\#5) }-3^{\text {rd }} . \text { Order bandpass } \\
\text { filter around } 110 \mathrm{~Hz} \cdot[13]\end{array}$ & $\begin{array}{l}\text { Switched Cap. \& } \\
\text { Continuous-time } \\
\text { preamp. }\end{array}$ & 4 & $6.9 \mu \mathrm{V}_{\mathrm{rms}}$ & $50-750$ & $1 \mu \mathrm{A}$ & $2-2.8 \mathrm{~V}$ & 1.9 \\
\hline
\end{tabular}

